\title{
Raised eyebrows as gestural triggers in humour: The case of sarcasm and hyper-understanding
}

\author{
Sabina Tabacaru ${ }^{1,2}$ \\ Maarten Lemmens ${ }^{1}$ \\ ${ }^{1}$ Université de Lille 3, France \\ ${ }^{2}$ Katholieke Universiteit Leuven, Belgium
}

\begin{abstract}
The growing interest in humour within the field of Cognitive Linguistics during the past few years has led to the conclusion that humour exploits inferences through linguistic imagery and is highly creative. Following Yus (2003: 1299), we assume that humour uses discourse markers that allow the audience to see that what is being said should not be taken seriously. In this study, based on a large corpus of examples extracted from two American television series (House M.D. and The Big Bang Theory), we add a yet unexplored multimodal perspective - that of facial expressions accompanying humorous utterances, particularly pertaining to sarcasm and hyper-understanding. More specifically, we present a qualitative and quantitative analysis of raised eyebrows used in interactional humour, arguing that they play a role in switching the context to a humorous interpretation. Our study analyses humorous utterances against the background of Clark's layering model and Fauconnier's mental spaces theory. We illustrate how raised eyebrows function as "gestural triggers" allowing the hearer to make the connection between explicature (i.e. what is explicitly communicated by an utterance; cf. Carston 2002, 2004) and implicature (i.e. assumptions that are not explicit and that the hearer has to infer from the contextual environment; $c f$. Grice 1989). As such, we show that raised eyebrows play an important role in the understanding of the humorous message because they guide the hearer to interpret utterances in a humorous way and they contribute to meaning construction.
\end{abstract}

Keywords: humour; cognitive linguistics; raised eyebrows; gestural triggers; gesture; discourse markers. 


\section{Introduction}

Since the publication of the Semantic Script Theory of Humor (Attardo \& Raskin 1991) and the General Theory of Verbal Humor (Attardo 1994), humour has been analysed from a more cognitive viewpoint, which not only views it as a complex phenomenon but also relates it more explicitly to the human mind (cf. Brône et al. 2006; Veale et al. 2006; Feyaerts 2006; Brône 2008; El Refaie 2011). The subjectivity of humour is one of the most widespread ideas in the field since something "can be humorous to one person, and utterly unfunny or even offensive to a different person or indeed to the same person under different circumstances" (El Refaie 2011: 87). Our purpose here is not to define the concept of humour, but, drawing on data from two television-series (House M.D. and The Big Bang Theory), to point out the contextual elements that help an audience perceive certain utterances as humorous. We thus focus on the role of raised eyebrows in interactional humour. Some of the questions that particularly concern us are the following:

- Are raised eyebrows relevant for the understanding of a humorous message?

- How can raised eyebrows help us perceive the speakers' humorous interpretation?

This paper emphasizes the need to extend existing humour analyses by integrating multimodality (specifically, raised eyebrows) as an important element leading to the interpretation of the humorous message.

As observed by Rockwell (2000), gestures and/or specific intonation are often used by speakers either to highlight chunks of their speech which are more important than others or in order to convey a certain meaning. Similarly, Müller (1998) talks about "discourse gestures" those gestures used to mark emphasis. Our study will narrow down the analysis of gestures to explore their role in the understanding of humour. As we will illustrate, raised eyebrows are used in our data to trigger or emphasise a humorous interpretation. In other words, when used with a humorous utterance, these gestural triggers help point out the element(s) that create(s) a humorous effect (the core humorous part of an utterance). The triggers contribute to the interpretation of the utterance in a humorous way, as well as to meaning construction.

Our study provides further evidence for the importance of analysing the multimodality of discourse, which encompasses talk, gesture and action, all coupled to the setting and purpose of activity (Williams 2008).

\section{Theoretical background}

\subsection{Humour in Cognitive Linguistics}

Two main theories ${ }^{1}$ that have been used in Cognitive Linguistics to analyse humour are Clark's (1996) theory of layered meanings and Fauconnier's (1984, 1994; Fauconnier \& Turner 1998) mental spaces theory. More importantly, these two theories have been unified in one perspective, discussed by Brône (2008). We briefly present the two theories below.

Clark's theory of layered meanings has been used for different phenomena, including humour. In his view, "layers are like theatre stages built one on top of the other" (Clark 1996: 16). For instance, a situation in which a boss dictates to his secretary a letter to his friend can be analysed as happening on two layers: Layer 1 - the actual conversation; and Layer 2 - 
addressing his friend in the letter (Clark 1996: 17). Clark notes that many conversations are structured in one layer, but the second layer is added in the case of humour. In other words, layering represents constructive discourse worlds based on "the surface level of the actual utterances" (Brône 2008: 2029). Just like other non-literal figures of speech, successful humour depends upon an apparent clash between what is said and what is intended (Sadock 1993: 42-43); reformulated in terms of Clark's theory, it involves a clash between Layer 1 and Layer 2. Figure 1 below represents the dynamics of three-dimensional layers, in which the higher level layer depends on the lower level layer. This figure, which we will return to later on in order to explain humour from a cognitive point of view, allows us to represent how meanings are related. Hearers will be able to shift from one interpretation to the other because there is at least one element that links them and because of the common ground between them (i.e. Layer 1).

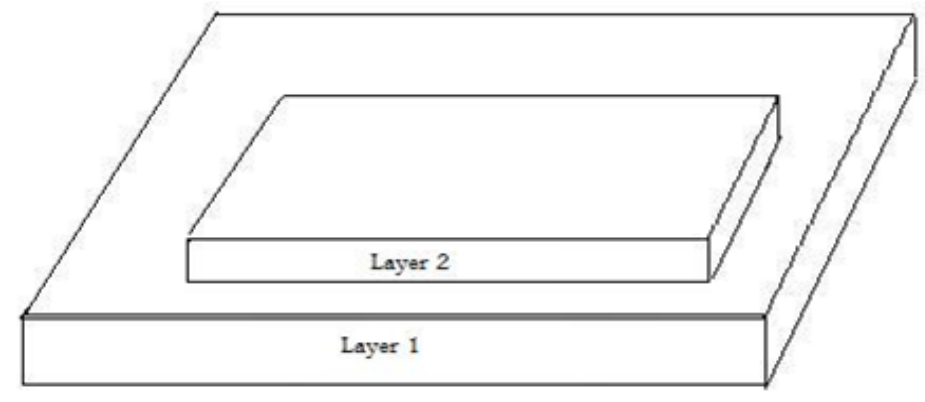

Figure 1. Clark's layering model

In order to understand how layering can unfold and explain humorous utterances, Clark (1996: 353) uses example (1), which is an exchange between a husband, Ken, and a wife, Margaret, regarding the husband's tutorial work. Ken mentions that he is not an expensive tutor, that he is cheap. Margaret's reply ("I've always felt that about you") echoes Ken's statement that he is cheap, but by doing so, she adds a new meaning to the situation as a whole. Clark categorises this as a tease, arguing that Margaret's reply does not represent a serious accusation, but rather pretence. This pretence is possible because of Layer 1 (i.e. the common ground between the two speakers). There is a serious-non serious perspective that is to be taken into account, as non-serious assertions (i.e. the pretence) are created from the serious conversation:
Ken:
and I'm cheap, - - -
Margaret: I've always felt that about you,
Ken: oh, shut up,
(- - - laughs) 15 bob a lesson at home

Fauconnier's (1984) mental spaces theory, which is the other primary theory used in Cognitive Linguistics in relation to humour (Coulson 2005b; Brône 2008), highlights the link between two (or more) different mental spaces or domains. ${ }^{2}$ Mental spaces are conceptual structures that "proliferate when we think and talk, allowing a fine-grained partitioning of our discourse and knowledge structures" (Fauconnier 1984: 11). Fauconnier notes that such constructs are developed from a pragmatic point of view because we are able to create links 
between different objects, events, physical entities, abstract concepts, etc. According to Coulson (2005a: 108), "when speakers produce language, listeners use that linguistic input along with background and contextual knowledge to set up simple cognitive models in mental spaces". Hence, people partition their knowledge into different mental spaces, "each structured by cognitive models from a relevant domain" (Coulson 2005a: 108). Moreover, Coulson (2005b) highlights the fundamental role of mental spaces theory in the processing of humour (and, more specifically, sarcasm) as not just simple opposition between what is said and what is meant, since it captures "the extent to which sarcastic utterances draw on our ability to understand mappings between normative and non-normative scenarios". Consequently, in order to understand humour, the human mind has to create and access different mental spaces.

Brône (2008: 2031) suggests that Figure 2 below provides the layered mental space configuration for example (1) by which he unifies these two accounts for the analysis of humour. Figure 2 illustrates how a pretence space is built on the discourse base space. The discourse base space is built on the 'literal' meaning of words, as intended by Ken, whereas the pretence space shows how the new interpretation is added to the context, as intended by Margaret's tease.

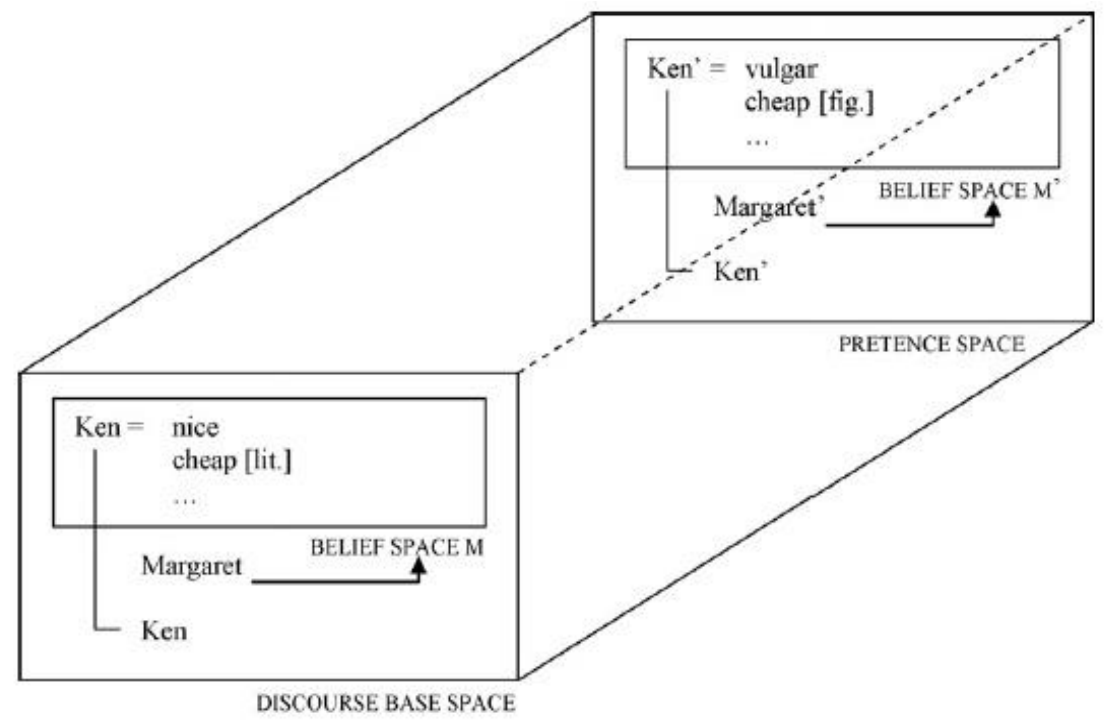

Figure 2. Layered mental space configuration for example 1 (Brône 2008: 2031).

The connector between the two mental spaces is the adjective cheap, which allows a new meaning to be added to the discussion. In the base space M (similar to Clark's Layer 1), Ken's interpretation of cheap is meant to be interpreted literally as 'inexpensive', whereas in the pretence space M' (Clark's Layer 2), the figurative meaning 'vulgar' is added to the context. As Kihara (2005: 516) puts it, mental space access explains how "two seemingly contradictory sentences are compatible". 3

To sum up, the concepts of layering and mental spaces show how people access information and are able to speak and communicate using the meanings stored in their memory (from previous discourse or background knowledge). Humour, as a type of discourse, behaves much in the same way and can be explained by drawing on these concepts. Discourse is manipulated in order to activate a different interpretation from the one that initially comes to mind, allowing a clash between two different layers or mental spaces. The key is to find the element(s) that are common to both interpretations and that make this switch possible. In the 
case of humour, both mental spaces theory and the three-dimensional model of layering reveal how meanings unfold when people communicate, and allow for multiple meanings to be built up one on top of the other. This is why Brône's account of humour will be used for the analysis of the examples in our study in section 4 below.

\subsection{Gestural cues for humour}

As noted by Davies (2008: 382-383), deciding between the meanings of utterances involves the inclusion of all available information in a given context: the teller, the audience, the tone, etc. Moreover, there is a growing interest in multimodality (Kendon 1980; McNeill 1985, 2008; Krauss et al. 2000; Calbris 2008; Cienki 2008; Mittelberg 2008, and many others), and, as our study shows, it is warranted for these elements to be included in the analysis of humour. The interest in the field of humour is still growing and there are only a few analyses on the role multimodality plays in relation to humour. The studies carried out so far single out two elements that appear to accompany humour: prosody ${ }^{4}$ and gestures.

Gestures (which can be of very different types) may precede, follow, or be used simultaneously with humour. Rockwell (2001) and Attardo et al. (2003) investigated the link between certain facial expressions and the use of sarcasm. As such, they note the use of eye rolling, rapid blinking, grimacing to inform the listener(s) that the meaning is sarcastic/ironic. More recently, Attardo et al. (2013) analysed the role of multimodality in conversational humour, yet they do not seem to consider them clear-cut markers of humour:

it is possible to find examples of humour accompanied by prosodic features associated with saliency, and it is possible to find several examples of humour preceded by significant pauses, and while it is also possible to find many examples of humour followed and/or preceded by laughter, we cannot claim that any of these features, with the exception of smiling, is a marker of humour. (Attardo et al. 2013: 412)

While we agree with their remark that analysing multimodality in humour is not an easy task, this kind of analysis should not be overlooked. The specifics and role of multimodal markers in humour still need a lot of research as they shed more light on the way humour is created and understood.

In this paper, we address a gap in the existing literature by focusing exclusively on raised eyebrows used with staged humorous interactions. We focus on the role these raised eyebrows play in the creation/interpretation of humour. In what follows, we present a brief description of gestures and facial expressions already presented in the literature, from which we will start our own investigation on the subject.

There are different types of gestures and their classification ${ }^{5}$ in the literature tends to vary. For instance, Müller (1998) (see also Cienki 2008) distinguishes between (a) discourse gestures, used to mark emphasis, (b) performative gestures, used when accepting or refusing an offer or idea, and (c) referential gestures, which refer to some abstract or even concrete idea or object. In our study, only the first type - that of discourse gestures - applies since raised eyebrows mark humorous interpretations and the switch to a pretence space. We show that raised eyebrows used together with humorous utterances tend to trigger the interpretation of an utterance as humorous and contribute to meaning construction by guiding the hearer to such an interpretation. 
Regarding facial expressions, Ekman (1979) draws up an overview of different eyebrow movements, as illustrated in Figure 3 below. ${ }^{6}$

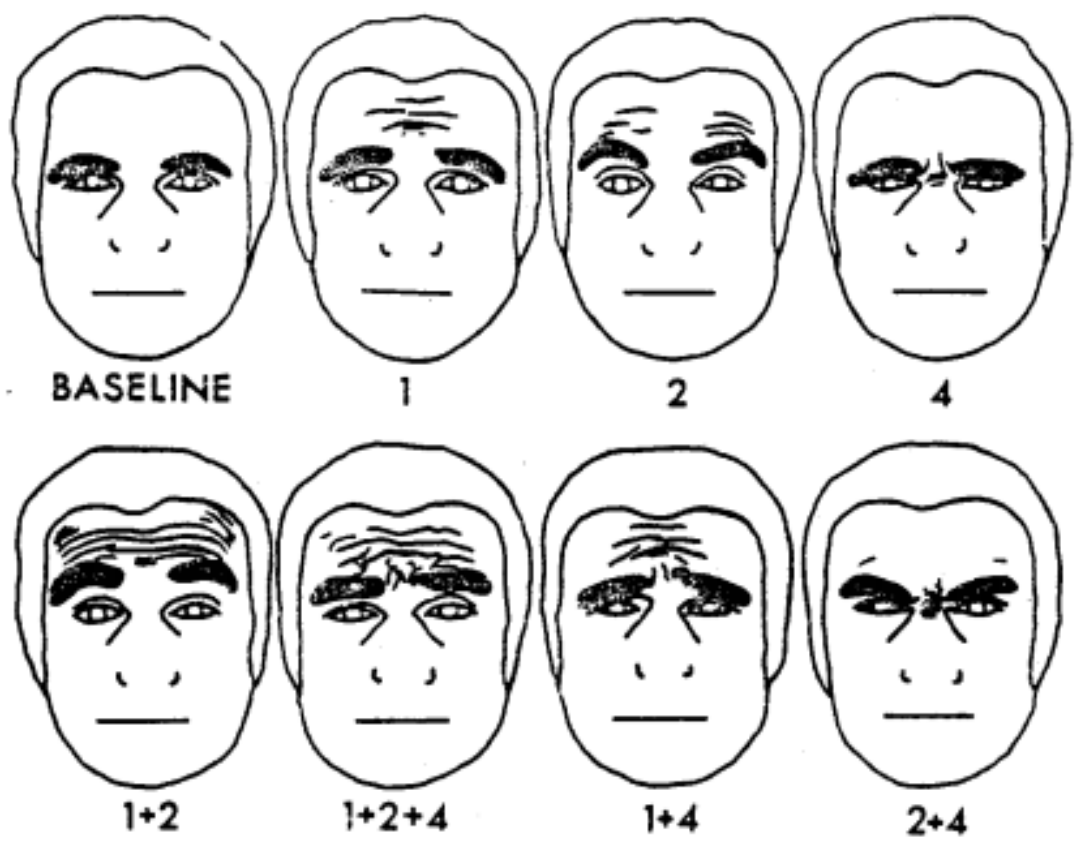

Figure 3. Eyebrow movement, according to Ekman (1979: 174)

The deviations from the baseline (the neutral face as represented by the first figure on the top left) concern both eyebrow movement and forehead movement, and Ekman associates the different movements with particular emotions - such as anger, fear, surprise, etc. (see also Darwin 1872; Ekman 1979; Ekman \& Friesen 2003). He also characterises eyebrow movements as underliners (Ekman 1979: 184) that provide emphasis for a given context. He further notes that people use mostly a sustained gaze and the expressions $1+2,4$, and $1+4$ in the figure above as underliners.

Next, we present the data and data analysis used in our study and recall Ekman's overview for the discussion.

\section{Case study: Humour in two contemporary American series}

Our corpus contains 800+ humorous tokens drawn from different seasons of two American series, House M.D. and The Big Bang Theory. These two series were chosen because of the contrast between them: while the latter is a widely known sitcom, the former one is a medical drama, which does include, however, a great deal of humorous instances, often characterised as irony and black humour. The corpus thus provides a wide variety of examples and situations, ranging from the daily life of successful but nerdy scholars to the medical environment and witty remarks of Dr. House (see also Dynel 2013).

The corpus consists of approximately eight hours of video recorded material from the two series, which represents more than 80,000 words. The randomly selected episodes were imported into $\mathrm{ELAN}^{7}$ which allowed us to annotate the data at different levels (called 'tiers' in ELAN). The analysis is done on five tiers: the verbatim transcription of the example, the 
humour type ${ }^{8}$, the semantic mechanism ${ }^{9}$, the associated gesture, and prosody (namely, sentence stress). The gestures and accenting of words were examined only in relation to the humorous utterances, as parts of the communicative setting in which humour appeared.

The purpose of this article is to focus on the role multimodality plays in the interpretation of humour, so the annotations concerned different kinds of gestures (facial expressions, head tilts, hand gestures, etc.). More particularly, we are interested in the role such gestures play in the creation/interpretation of humorous utterances. We will focus on one of the facial expressions most commonly used in conjunction with humour: that of raised eyebrows. ${ }^{10}$ Eyebrow movements mark a certain attitude of the speaker (and thus mark the entire utterance) or emphasise a certain part of the discourse (thereby marking just certain words). The focus is then drawn to the way multimodal elements alert the hearers to switch to a pretence space or a non-serious layer that connects to the discourse space (see section 2.1. above).

In the next section, we focus on the humour types that co-occurred more frequently with raised eyebrows in our study: sarcasm and hyper-understanding.

\section{Raised eyebrows in sarcasm and hyper-understanding}

In what follows, we will take a closer look at some examples drawn from our corpus, which will point to the necessity of taking into account raised eyebrows in the understanding of humour. By attracting the hearer's attention, these elements can focus on only some parts of the discourse which are more relevant than others. From all the humour types ${ }^{11}$ encountered in our data, for the present discussion we chose some representative examples of sarcasm and hyper-understanding because they were more frequently associated with raised eyebrows in our data.

For the purpose of this study, sarcasm and irony can be considered as sufficiently similar, even if there is some discussion in the literature whether they are indeed the same. Sarcasm has often been equated to irony, the main difference being that it is more aggressive than irony (Lee \& Katz 1998; Mesing et al. 2012). At the same time, as Attardo (2000: 795) points out, "there is no consensus on whether sarcasm and irony are essentially the same thing, with superficial differences, or if they differ significantly". Wilson \& Sperber's (2012) view on irony is that it represents an echo of a thought or a belief and it expresses a mockery or criticism of the aforementioned thought or belief. Seen from this perspective, both irony and sarcasm can be defined as the opposite of what the speaker said. Example (2) below, taken from McCarthy \& Carter (2004: 153; see also Sanders 2013 for a discussion) is considered sarcastic:

Radio: In the IRA bomb attack on Manchester ten days ago, they say two or more Irish men might have been together in the Greater Manchester area.

P1: Oh right.

P2: Oh great [Laughs] Oh bloody brilliant!

P1: Well that'll narrow it down a bit, won't it?

As noted by Sanders (2013: 120), all three reactions are sarcastic, but probably the clearest is the last one. These reactions underline the mockery toward Manchester, as well as an incongruity between what is said and what is thought of Manchester. The adjective great is 
used here mockingly since saying that'll narrow it down a bit implies (Grice 1989) that it is actually the opposite of great.

The term 'hyper-understanding' was coined by Veale et al. (2006) and has been defined as revolving "around a speaker's ability to exploit potential weak points in a previous speaker's utterance by playfully echoing that utterance while simultaneously reversing the initially intended interpretation" (Brône 2008: 2027). Brône (2007, 2008) points out that hyperunderstanding hinges on layering (discussed above) or on a key element that makes the reversing of the intended interpretation possible. Even though it can be of different kinds depending on the linguistic mechanisms creating the hyper-understanding (see Brône 2008 for details), we will only focus on those cases of hyper-understanding that co-occur with raised eyebrows. ${ }^{12}$ Example (3) below is an instance of hyper-understanding, discussed in more detail in Veale et al. (2006):

$$
\begin{aligned}
& \text { G.B. Shaw: Here is an invitation to the opening night of my new play. } \\
& \text { Bring a friend, if you have one. } \\
& \text { Churchill: } \quad \text { I'm afraid I can't make it on the opening night. } \\
& \text { But I may attend on the second night, if there is one. }
\end{aligned}
$$

Here, the if-clause is repeated by Churchill in order to turn the tables on G.B. Shaw. By saying if you have one [friend], G.B. Shaw is implying that Churchill may not have any friends. Hyper-understanding occurs here when the same if-clause structure is repeated and used against G.B. Shaw with the remark if there is one [second night], where the implication is that the play may be so bad that there may not be a second night. This is what Veale et al. (2006: 315) call structural parallelism. Veale et al. (2006: 312) also propose the following schema to account for hyper-understanding:

$\mathrm{S} \quad$ Opens with an utterance $\mathrm{U}$ containing a specific idea $\mathrm{X}$ where $\mathrm{U}$ serves a communicative goal $\mathrm{G}$ (e.g., $\mathrm{G}=$ self-praise, insult, persuasion, consolation, etc.)

$\mathrm{H} \quad$ Responds with an utterance U' containing an idea $\mathrm{X}^{\prime}$ that is parallel to $\mathrm{X}$ so that U' serves a competing or contrary communicative goal $\neg \mathrm{G}$ $\mathrm{U}$ ' subverts $\mathrm{U}$ and $\mathrm{H}$ trumps $\mathrm{S}$ to the extent that $\mathrm{X}^{\prime}$ is apropos to $\mathrm{X}$

The second speaker's utterance (U') must parallel the first speaker's initial utterance (U) "in some key aspect, whether phonetic, lexical, structural or conceptual to achieve the effect of neutralizing U using the S's own language choices" (Veale et al. 2006: 312). In example (3), hyper-understanding takes place at a structural level, where the if-clause is repeated by Churchill in his reply.

In our data, both sarcasm and hyper-understanding repeatedly co-occur with raised eyebrows. We first discuss some examples of raised eyebrows with sarcasm (two from House M.D. and one from The Big Bang Theory) and subsequently analyse three examples of hyperunderstanding (one from House M.D. and two from The Big Bang Theory).

\subsection{Sarcasm}

Sarcastic utterances make up 35.5\% of our corpus (306 tokens). Sarcastic utterances, as pointed out by Boxer (2002) and Cheang \& Pell (2009), bear specific intonation. Rockwell 
(2001) makes a link between sarcasm and facial expressions. As these studies show, speakers tend to mark explicitly via intonation or facial expressions that they are being sarcastic so that an audience (watching the show) would correctly interpret their utterances as referring to a Layer 2 or a pretence space. The message can thus be interpreted as a non-serious message (in Clark's terms). Even if we are not comparing our data to spontaneous humour, it is fairly safe to assume that, in staged interactions, such markings of sarcasm would be more visible since the actors know beforehand they are going to be sarcastic and they might exaggerate certain reactions. $^{13}$

Example (4) below, drawn from the House M.D. corpus, is categorised as sarcasm in which the speaker (Dr. House) uses raised eyebrows (place of occurrence marked in bold). Dr. House is in the consultation room with Ricky, a young man, and his father, who does not talk at all during the consult.

Ricky: He can't talk.
House: Excuse me?
Ricky: He had knee surgery.
House: Right...
Ricky: About a year ago, and then he couldn't talk.

House: Right, yeah, well, that happens. You know, it's very dangerous operating so close to the vocal chords.

In this example, Dr. House is sarcastic and his utterance means the opposite of what he says because he does not really believe that one can lose their voice after knee surgery. This is an implicature (cf. Grice 1989) derived from Ricky's utterance and then he couldn't talk, wherein then marks the loss of the voice after the knee surgery. Sarcasm is underlined by the use of the adjective dangerous, which also corresponds to the moment when House raises his eyebrows to alert the hearer of the pretence of his utterance; it is the key in terms of which the opposition should be interpreted. The audience (at home, watching the show) is able to access the pretence space (the non-serious space) and interpret this as sarcastic, as the opposite of what he is saying. Sarcasm is the layered meaning built on the common ground that the audience shares with the speaker. The video stills in Figure 4 below show how Dr. House raises his eyebrows when uttering the word dangerous to highlight that this is the most nonserious word of his message (i.e. the core of the humorous message). In this way, he points out that the discourse space has been reversed with a pretence space, where it is possible for one to lose their voice after a knee surgery.

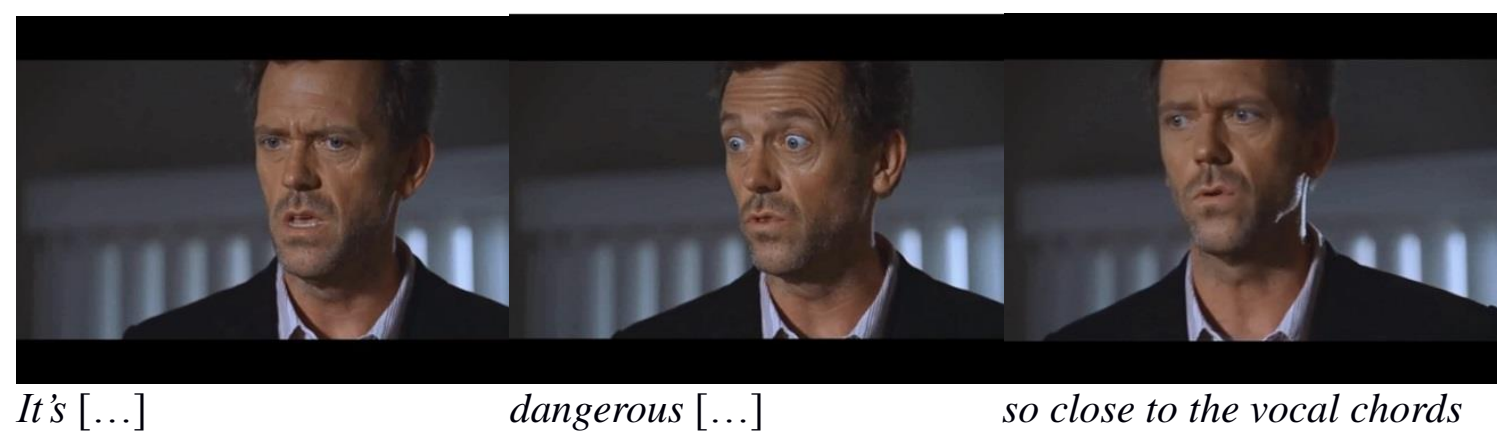

Figure 4. Raised eyebrows in Example (4) 
As shown in Figure 4, if the other two frames show the speaker frowning while uttering the sarcastic message, it is only when using the adjective dangerous that he changes his gestural attitude and raises his eyebrows. Through the gestural focus on this adjective, the audience is able to retrieve the non-seriousness of his words, and interpret them as the opposite of what he is saying, particularly in view of what is to follow (close to the vocal chords). In a Gricean analysis, the adjective dangerous is considered to be the verbal trigger for the audience to infer the speaker's intended implicature between what is said and what is meant (cf. Grice 1989); in a similar vein, the raised eyebrows that co-occur with the humorous utterance and further reinforce it can be regarded as what we term a gestural trigger. Our term gestural trigger refers to the gesture that guides the hearer to interpret the utterance as humorous and contributes to meaning construction (i.e. how the hearer interprets the message).

Similarly, in example (5) below, taken from The Big Bang Theory, the speaker (Beverley) raises her eyebrows to mark her sarcastic attitude. The speech is uttered slowly; sarcasm is thus also emphasised by prosody. The difference with example (4) is that the raised eyebrows are kept throughout her utterance, and the gesture is not limited to one word only. It appears that the gesture highlights the central humorous part, be it a word or a clause. Beverley, a psychiatrist, believes that Rajesh and Howard have homosexual feelings toward one another, which they refuse to admit. Howard mentions that he has a girlfriend, which is an argument against Beverley's claim. Again, the words in bold correspond to the raised eyebrows used by the speaker:

(5) Howard: We don't have latent homosexual feelings toward one another.

Beverley: I see.

Howard: No, really, I have a girlfriend now.

Beverley: And where is she this evening?

Howard: She had to go out of town, her grandmother died.

Beverley: I see (smiles, pauses) Her grandmother died.

Similar to example (4) above, it is clear that the speaker is being sarcastic and she does not want her words to be taken at face value. Specifically, example (5) is built on the repetition of the exact same words that the previous speaker used. She thus creates an echo ${ }^{14}$ (as discussed by Wilson \& Sperber 2012 mentioned above). Beverley's interpretation places Howard's utterance in a pretence space which contains the humorous interpretation of the same utterance. As such, her grandmother died is first placed in Layer 1 (the serious discourse space) when uttered by Howard, and then moved to Layer 2 (the non-serious, pretence space), which is triggered by Beverley's attitude toward what the first speaker (Howard) said. Two mental spaces are accessed in this process since the same input (the same words) mean different things according to the person uttering them. The video stills in Figure 5 below show Beverley raising her brows when she repeats Howard's words. 


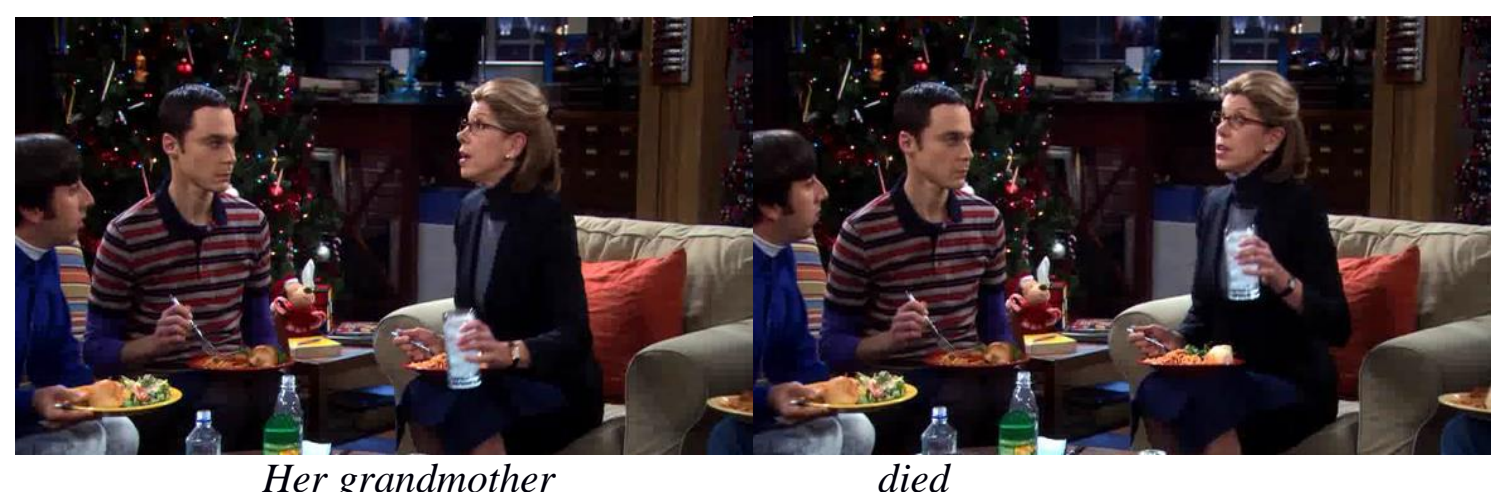

Figure 5. Raised eyebrows in example (5)

Besides raising her eyebrows, the speaker also rolls her eyes toward the end of her message, which further emphasises the non-serious attitude she shows toward Howard's words. Clearly, she is mocking Howard's defence by just repeating in a sarcastic way what he said before. Following Brône (2008), we suggest Figure 6 to account for example (5):

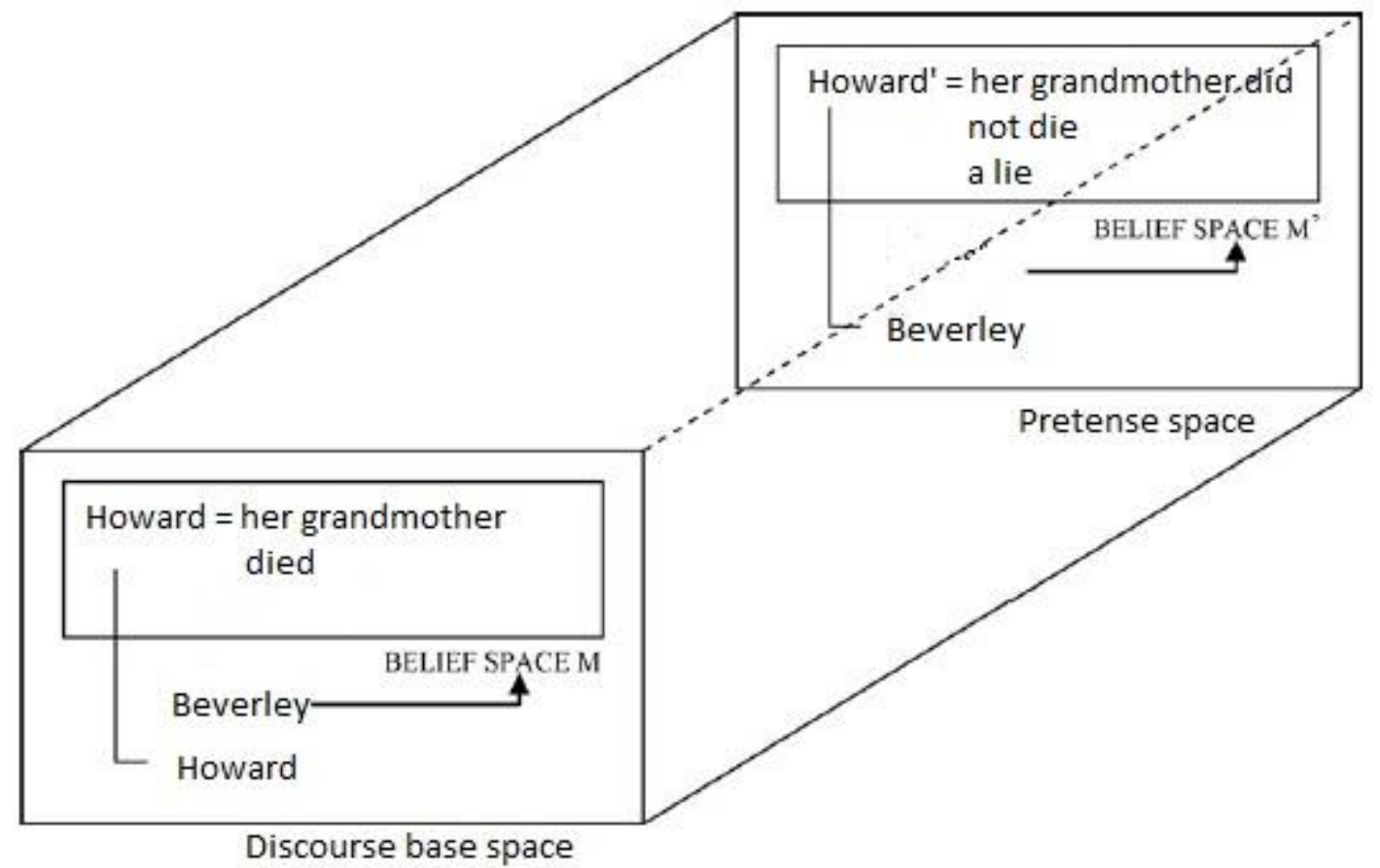

Figure 6. Layered mental space configuration for example (5)

Example (6) below, taken from House M.D., presents another case of raised eyebrows co-occurring with sarcasm. The scene takes place after Dr. House decides to play a game where the 'contestants' (his team) have to bring him their boss's underwear. The team slowly gets up and starts walking toward the door, when they stop before passing another doctor, Foreman, who is reading a newspaper. The words in bold mark the raised eyebrows in his speech:

(6) Foreman: It's how I got hired. 
Similar to example (5), the speaker (Foreman) raises his eyebrows while uttering the entire sentence (as shown by the stills in Figure 7 below). Clearly, his sentence is not to be interpreted at face value, since the game Dr. House is playing is absurd and getting hold of the boss's underwear cannot be a criterion for being hired as a doctor. Thus, Foreman manages to switch to a non-serious space where this type of game becomes some sort of condition in order to become a doctor. Unlike example (4), where the core humorous message was highlighted by one word only, this instance is not formed on only one word that marks the sarcastic meaning. Rather, it is the entire utterance that is sarcastic, similar to (5) above. This example does not build on just repeating an interlocutor's words, but uses the common ground already formed by House's game in order to give a new non-serious twist to the situation.

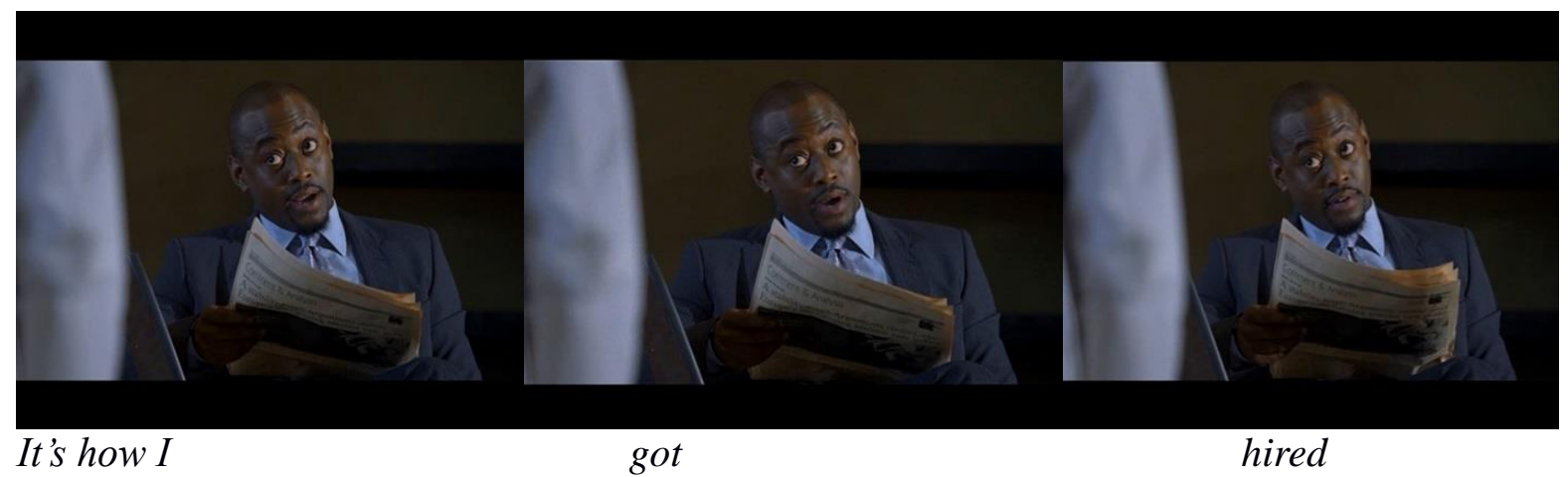

Figure 7. Raised eyebrows in example (6)

Next, we discuss examples drawn from our corpus that display raised eyebrows cooccurring with hyper-understanding.

\subsection{Hyper-understanding}

As defined above, hyper-understanding consists of a "sudden manipulation of the discourse space that has been set up in the previous utterance" (Veale et al. 2006: 305). Potential weak spots in previous utterances are used in order to give a different meaning to the message (Brône 2008: 2028). In our study, hyper-understanding makes up 11.03\% of the total corpus (with 95 tokens).

In example (7) below, the raising of the eyebrows coincides with the element that emphasises a sexual interpretation and the humorous part of the utterance. In this particular context, House runs into Mark who is married to House's ex-fiancée. The scene presents Mark in a wheelchair after he got into an accident. Similar to the previous examples, the words in bold mark the use of raised brows (shown in the video stills in Figure 8 below).

House: How's your recovery going? Got around to the small muscles yet?

Mark: It's not the size of the muscle; it's where you get to put it.

Clearly, House's initial remark was aimed at ridiculing his adversary by referring to the size of his muscle. The 'small' muscle in this context has a sexual connotation which Mark manages to trump accordingly: he repeats House's implication, but turns the tables on him by reminding him that it is not the size that counts, but where he gets to put it. In this way, he reminds House that his ex-fiancée is now married to him. The sexual implicature was already 
present in House's previous utterance, but hyper-understanding consists of reversing the situation where Mark, despite his 'small muscle', becomes a winner because he is the one who is now married to House's ex-fiancée. Figure 8 below shows the way the raised eyebrows emphasise hyper-understanding.

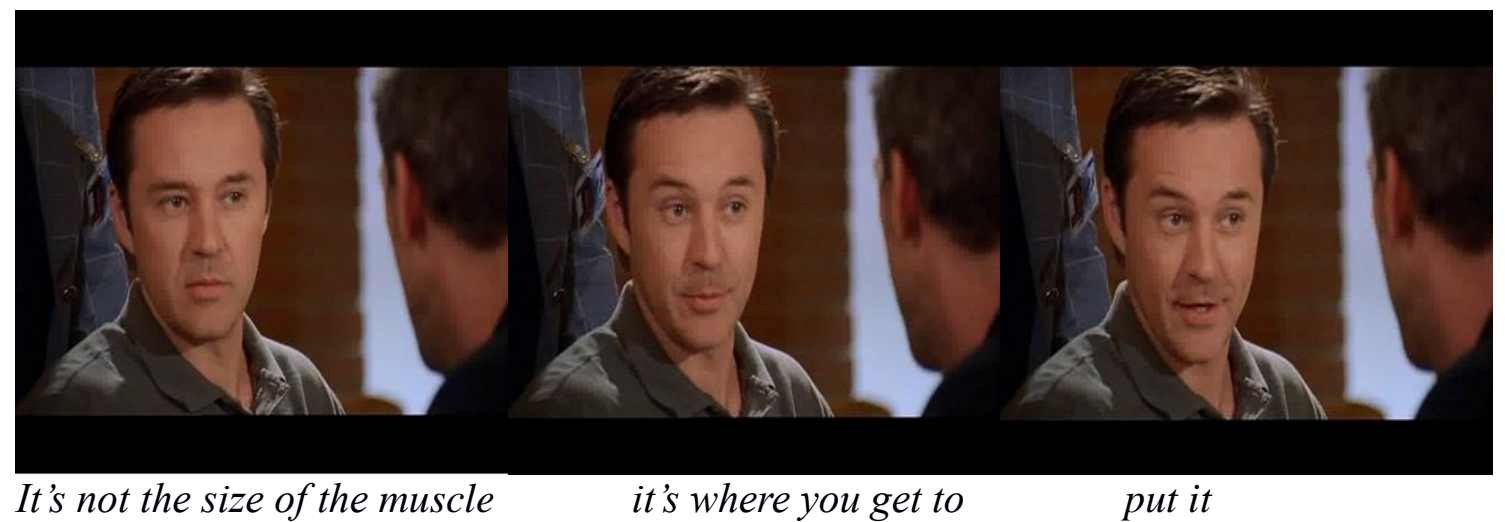

Figure 8. Raised eyebrows in Example (7)

The speaker keeps a straight face when repeating the interlocutor's (House) words, but raises his eyebrows when hyper-understanding takes place. The gaze is added in the third frame (put $i t$ ) and also underlines the sexual connotation (i.e. expressing something like if you know what I mean'). The layered meaning is built in the third frame when Mark uses the raised eyebrows as gestural triggers of his humorous implication. The common ground (Layer 1) is created by the previous discourse (House's own words) and the knowledge already shared by the speakers (i.e. that Mark is now married to House's ex-fiancée). The mental spaces accessed/created in this example are built on the sexual connotation of the speaker(s).

Consider also example (8) below, taken from The Big Bang Theory corpus. This time, the raised eyebrows are used when the key element (expect) of hyper-understanding is repeated in the second utterance in order to shift the meaning to a new interpretation. Howard sees his friend Sheldon with an attractive girl whom he has never seen before. His conversational opener is meant to impress the girl as he finds her very attractive. When Sheldon, misunderstanding Howard's utterance, mentions that he was not "expecting" him, Howard takes advantage of Sheldon's choice of words to introduce himself to the girl:

(8) Howard: Sorry I'm late; I'm working on a project that may take me up on the next space shuttle.

Sheldon: How can you be late, I wasn't expecting you at all.

Howard: Nobody ever expects me, sometimes you just look and... BAM (shakes girl's hand) Howard Wolowitz.

Sheldon here misinterprets ${ }^{15}$ the conversational opener (also, Howard's way to show off) and uses the verb expect, which is then repeated and its interpretation is reversed and exploited by Howard to introduce himself to the girl. The stills in Figure 9 present hyper-understanding by virtue of the raised eyebrows when the speaker repeats the verb expect and then the following line that keeps the pretence space. 


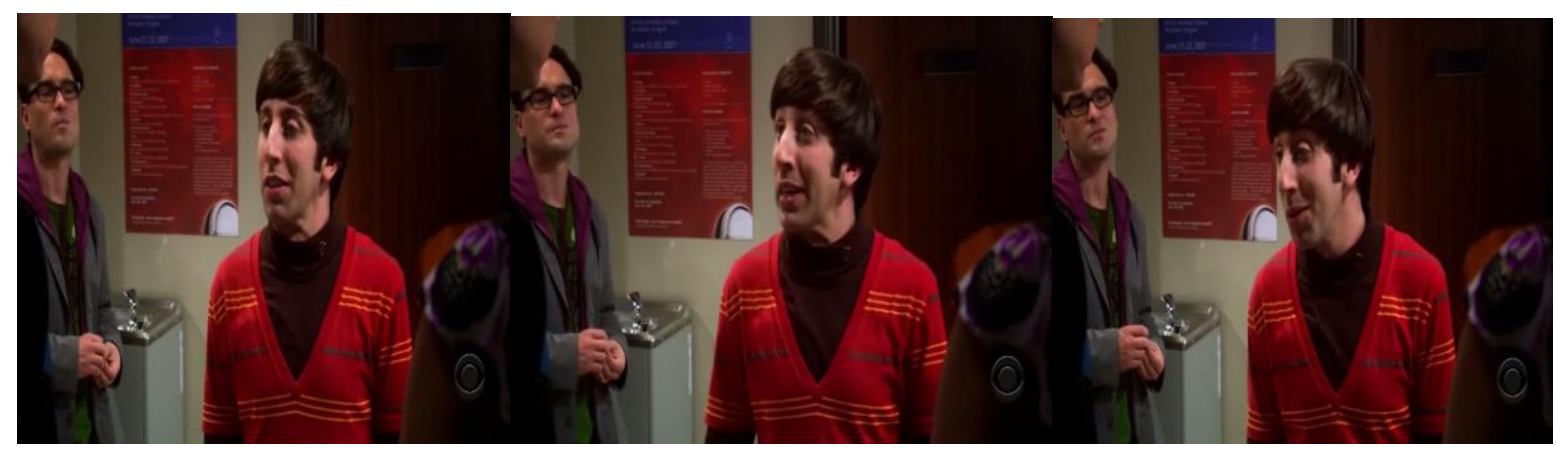

Nobody ever

expects me

sometimes you just look

Figure 9. Raised eyebrows in example (8)

Hyper-understanding is triggered here by the key element expect, whose meaning is exploited for Howard's own rhetorical goals. The raised eyebrows are here used in a different way compared to example (7) above. In (7), the speaker raised his eyebrows to highlight the sexual interpretation of his utterance (already existent in the previous speaker's utterance), whereas in (8) it triggers a completely new meaning. It also comes as a mockery of what the previous speaker said (i.e. no one can expect him, he comes as a surprise). Similar to example (5), the speaker here repeats the previous speaker's words but not to mock them (as in example 5). He reverses the situation and turns the tables for his own rhetorical goals, thus managing to make an appearance and introduce himself to the girl.

Similarly, example (9) below also comes from The Big Bang Theory corpus. We see Sheldon working in front of his computer while his sister (whom he does not see often) talks to his friends on the couch. The words in bold mark the raised eyebrows in his utterance (see the video stills in Figure 9 below):

(9) Penny: Sheldon, why are you ignoring your sister?

Sheldon: I'm not ignoring my sister; I'm ignoring all of you.

This is a case of structural hyper-understanding (Veale et al. 2006; Brône 2008), where a speaker uses the exact structure as the previous speaker but shifts the meaning to a new interpretation (see also example 3 above). As such, the speaker (Sheldon) switches the utterance from your sister to all of you. The raised eyebrows (see Figure 10) start when the speaker utters the verb ignoring but are more visible at the end of the utterance when he says all of you, marking in this way the part of the sentence that represents the turning of the tables and the new humorous meaning given to the utterance.

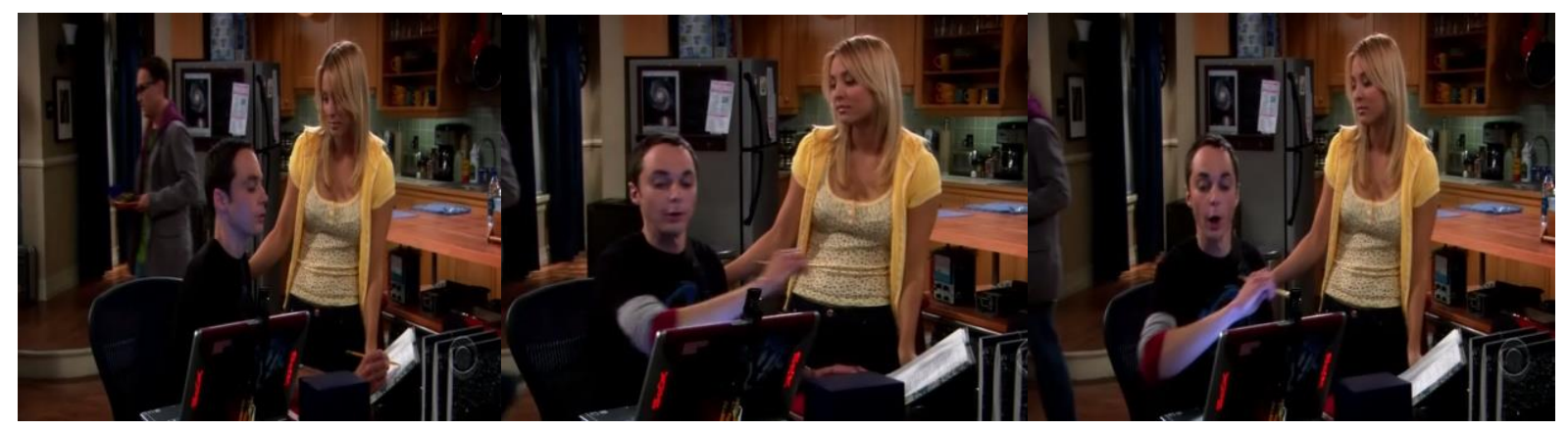

Not ignoring my sister

ignoring

all of you

Figure 10. Raised eyebrows for example (9) 
As shown in Figure 10, when repeating the previous speaker's (Penny) utterance (I'm not ignoring my sister), the speaker does not raise his eyebrows (as in example 5 above), but this happens only when adding the new interpretation (I'm ignoring all of you). The raised brows mark the humorous interpretation of the new utterance, the pretence space (also, Layer 2) created from the discourse base space. The common ground is built by repeating the interlocutor's words (I'm not ignoring my sister), but humour is marked in the pretence space by the new meaning added to the context (ignoring all of you).

We further propose a more detailed analysis for the use of raised eyebrows co-occurring with humour, basing these remarks on the results given in our study.

\section{Discussion}

While we have considered only a handful of examples, they clearly show that raised eyebrows play an important role when used in humorous utterances. The specific functions of the raised eyebrows can be numerous: they may emphasize the one element that triggers the switch to a pretence space (as in example 4 above), they may comply with a certain attitude that manifests itself in speech (as in examples 5 and 6), or they may trigger a new interpretation that continues afterward (examples 7, 8, and 9). At a more general level of analysis, they can all be considered gestural triggers that highlight the speaker's attitude and mark the nonseriousness of the utterance, facilitating the audience's access to the pretence space of the intended implicature of the utterance.

This is confirmed by the frequency with which raised eyebrows are used with sarcasm and hyper-understanding in our corpus, as shown in the chart below. The table presents three categories: sarcasm, hyper-understanding, and sarcasm combined with hyper-understanding (i.e. utterances that involve both sarcasm and hyper-understanding). As shown, more than half of the tokens in our case study co-occur with the use of raised eyebrows (namely, 58.4\% tokens for sarcasm, 46.3\% cases for hyper-understanding, and $89.4 \%$ of sarcastic hyperunderstanding), which sustains our claim that raised eyebrows function as gestural triggers in interactional humour. There seems to be a pattern where speakers alert the hearers and the audience of the humorous interpretation of their message. 


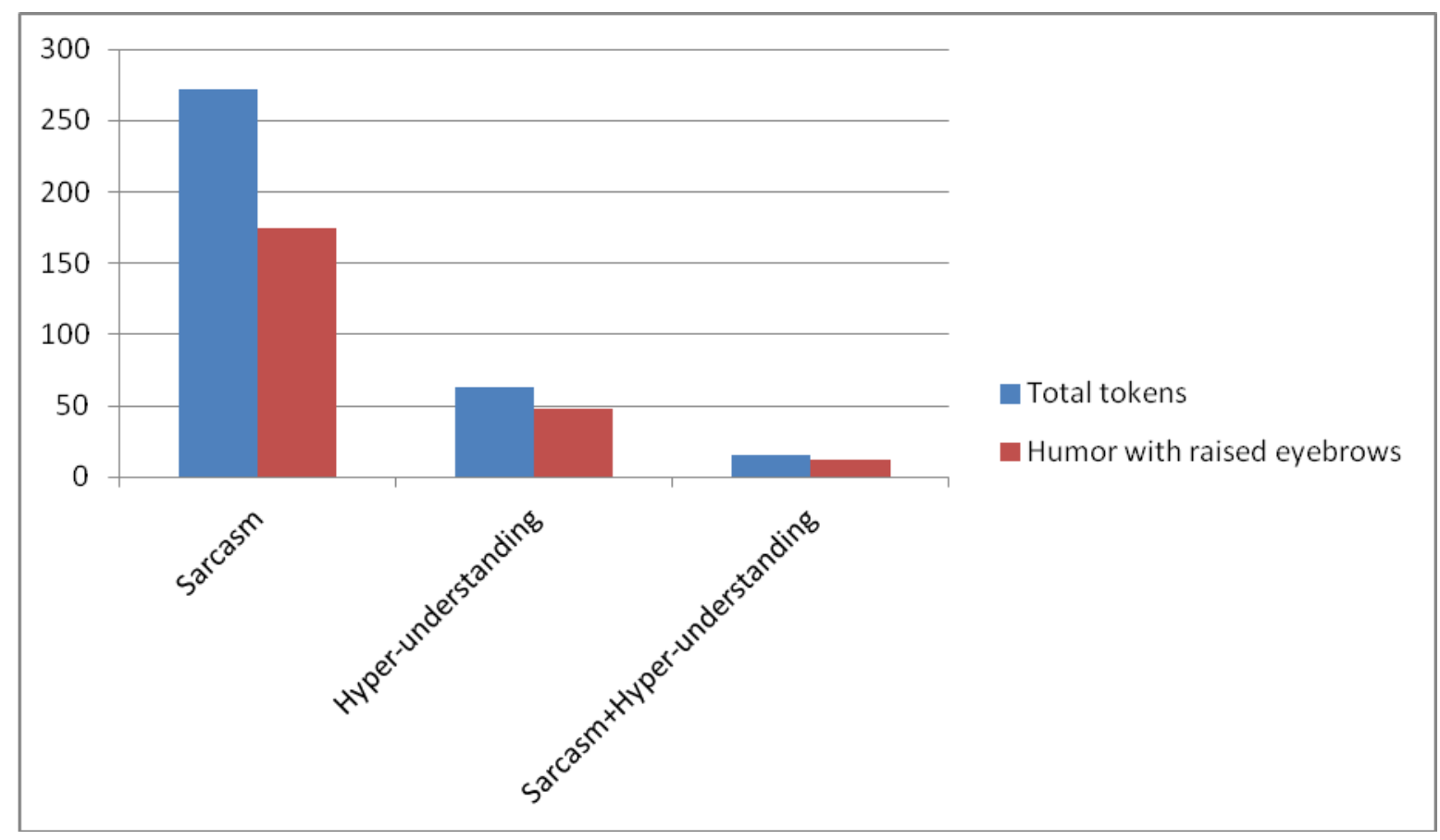

Table 1. Tokens used with raised eyebrows in our case study

Humour analysis is a challenging field because it is often open to interpretation and debate. Furthermore, analysing gestures with humour seems to be a daunting task because of the numerous functions that can be attributed to this relation, as shown by the examples discussed above. Yet, as shown by the proposed analysis, raised eyebrows (and, including the broader picture, facial expressions and gestures) should not be ignored when analysing humour.

Taking Ekman's perspective as a starting point for our analysis, we can make two hypotheses regarding the role of raised eyebrows: a pragmatic and a semantic one. The first hypothesis, which is in line with our own claim, sees these facial expressions as pragmatic markers of humour, as also suggested by Ekman's term underliner. This does not mean, however, that, when people raise their eyebrows, humour is necessarily happening or about to happen. In other words, raised eyebrows do not predict humour. Facial expressions would only be pragmatic markers, highlighting the humorous trigger (a certain attitude or word), as part of the expression of a speaker's attitude (just like tone of voice), and, thus, helping the hearer to understand the intended meaning. The gestures come as 'helpers' toward the intended interpretation, but it does not work both ways, i.e. people raising their eyebrows do not necessarily mean that they are using sarcasm/hyper-understanding.

The second hypothesis takes a more semantic perspective and sees the eyebrow movements co-occurring with humour as expressions of human emotions. A gesture such as 1+2 (see Ekman's perspective in Section 2.2) has been said to be an expression of surprise or interest (Ekman 1979: 201); its co-occurrence with humour can thus be accounted for by seeing humour in terms of surprise (Janko 1984, Attardo 1994, Perks 2012). Research in the field of humour reveals that speakers indeed manipulate the discourse space in order to surprise the hearers with new readings (cf. Raskin 1985; Brône \& Feyaerts 2003; Yus 2003, etc.). Clearly, it would make sense to assume that speakers use the element of surprise when they use humour. Note, however, that while these facial expressions usually indicate receiver's surprise, in humorous exchanges such as the ones analysed here, it is the speaker 
who raises the eyebrows. Given that our data involve staged interactions, where speakers know beforehand that they are going to use humour and might exaggerate their reactions, the analysis of facial expressions as expressing the element of surprise (which happens when discourse moves to a pretence space) may still be valid. The question remains open as to how similar gestures are used with spontaneous humour and whether both of our hypotheses would then still apply. While these two hypotheses are not necessarily mutually exclusive, we are more inclined toward the pragmatic analysis of seeing raised eyebrows as gestural triggers of humorous inferences.

\section{Concluding remarks}

On the basis of examples from two contemporary American television-series, we have discussed the role that raised eyebrows play in the interpretation of humorous messages. Our data on raised eyebrows used with sarcasm and hyper-understanding reveal the importance of such gestural elements for the understanding of the humorous message by an audience who has access to the visuals, in addition to the audio. Raised eyebrows play an important role in emphasising or triggering the humorous interpretation; for that reason, we have called them gestural triggers. Essentially, they mark the speaker's attitude of non-seriousness, guiding the audience to access the pretence space. They alert the hearer of the core humorous message in their discourse and contribute to meaning construction because they give access to humorous interpretation(s). The pretence space is where humour takes place and builds on the common ground between speakers and the audience in this case. In other words, the examples discussed here can easily be analysed using Clark's layering model and Fauconnier's mental spaces, which involve a non-serious, pretence space, built on a serious discourse space. The raised eyebrows used by the speakers can be seen as pragmatic or semantic triggers that mark the switch to the second, non-serious layer.

However, given our exclusive focus on raised eyebrows, many questions remain to be answered, particularly because the functions of gestures are numerous. Our study reveals nonetheless their involvement in perceiving an utterance as humorous. In addition, our study is based on staged interactions of humour, where writers, producers, and actors consciously work together to help an audience see the humorous message. Our analysis is merely the onset of more extensive future research on the role gestures play in the production of humour, paying particular attention to humour in spontaneous conversations. Finally, we have limited our analysis to humorous exchanges; more work is needed to see how facial expressions (and other discourse gestures) function in speech in general.

\section{Notes}

${ }^{1}$ There are a number of competing theories that provide explanations on humour interpretation, such as Attardo et al.'s (2002) structure mapping. Nonetheless, the cognitive mechanisms discussed in cognitive linguistics provide a more clear-cut analysis of humour understanding/production (cf. Brône \& Feyaerts 2003).

${ }^{2}$ For more on frames, idealised cognitive models, or domains, see Radden \& Kövecses (1999).

${ }^{3}$ Similar to this view is the idea of script-opposition (Raskin 1985; Attardo \& Raskin 1991; Attardo 1994) where two scripts can overlap or oppose each other in order to create humour. A certain connector makes the switch possible from one interpretation to the other. See also Koestler's (1964) idea of bisociation, where humour is possible because of the incompatibility between two matrices. 


\footnotetext{
${ }^{4}$ Prosody can mark a different tone of voice that is used with sarcasm or irony (Clark \& Gerrig 1984; Sperber 1984). For instance, Rockwell (2000) carried out some experiments revealing that speakers are able to recognise a sarcastic tone used in sarcastic utterances (for the purpose of this study, we consider sarcasm to be a case of humour, even if the issue is much more complex than this, cf. Hidalgo Downing \& Iglesias Rescuero 2009). Rockwell's (2000: 493) experiment nicely shows that "sarcasm appears to exhibit a clear pattern of vocal cues". Similarly, Boxer (2002) and Cheang \& Pell (2009) note that speakers raise the fundamental frequency of their voice when using sarcasm.

${ }^{5}$ See also McNeill's (1992: 76) scheme of gesture classification, which includes different typologies.

${ }^{6}$ See also Bartlett et al. (1999) where they mention types of brow movement, or Ekman (1999) for more nonverbal signals in speech.

${ }^{7}$ ELAN is a tool for video annotation freely available for researchers from the Max Planck Institute for Psycholinguistics, The Language Archive, Nijmegen, The Netherlands (http://tla.mpi.nl/tools/tlatools/elan); see Sloetjes \& Wittenburg (2008).

${ }^{8}$ Concerning the humour types, we have used Feyaerts' (2013) typology that brings together all the classifications in the literature so far. This is the classification used for the Corinth corpus (Feyaerts et al. 2007), a corpus of Dutch humour, which was created and analysed by Kurt Feyaerts, Geert Brône, and Bert Oben from the University of Leuven.

${ }^{9}$ By semantic mechanism, we understand the analyses in the literature review: from Grice's (1989) implicature, to Sperber \& Wilson's (1988) inference, script-opposition (Raskin 1985; Attardo \& Raskin 1991) and Croft \& Cruse's (2004) construal operations (see also Brône \& Feyaerts 2003 for a more detailed analysis on how these construals can be exploited in humour).

${ }^{10}$ From all the gestures annotated in the corpus (hand gesture, head tilt, shrug, nod, etc.), raised eyebrows were the ones most frequently encountered with humorous utterances ( \pm 500 occurrences with humorous mechanisms).

${ }^{11}$ Feyaerts (2013) presents 23 types of humour.

${ }^{12}$ In other words, the focus is not on a typology of hyper-understanding (as already presented by Brône 2008), but on cases of hyper-understanding co-occurring with raised eyebrows.

${ }^{13}$ See also Rockwell (2000) who used people with professional acting experience for the reading out of sarcastic utterances. Her hypothesis was that trained individuals would "exhibit more expressive voices" (Rockwell 2000: 488) than any other volunteers.

${ }^{14}$ It has been suggested that irony has an echoic use (Sperber \& Wilson 1981; Barbe 1995; Wilson $\&$ Sperber 2004). The speaker echoes a thought (or an opinion, hope, expectation, etc.) and thus expresses the opposite of that thought (or opinion, hope, expectation, etc.).

${ }^{15}$ Misunderstanding is the opposite of hyper-understanding and can also be a type of humour, as discussed by Brône (2008).
}

\section{References}

Attardo, S. (1994). Linguistics Theories of Humor. Berlin/New York: Mouton de Gruyter. Attardo, S. (2000). 'Irony as relevant inappropriateness'. Journal of Pragmatics 32 (6), pp. 793-826.

Attardo, S. \& Raskin, V. (1991). 'Script theory revis(it)ed: Joke similarity and joke representation model'. Humor: The International Journal of Humor Research 4 (3/4), pp. 293-348.

Attardo, S., Hempelmann, C. F. \& Di Maio, S. (2002). 'Script oppositions and logical mechanisms: Modelling incongruities and their resolutions'. Humor: International Journal of Humor Research 15 (1), pp. 3-46. 
Attardo, S., Eisterhold, J., Hay, J. \& Poggi, I. (2003). 'Multimodal markers of irony and sarcasm'. Humor: The International Journal of Humor Research 16 (2), pp. 243-260.

Attardo, S., Pickering, L., Lomotey, F. \& Menjo, S. (2013). 'Multimodality in conversational humour'. Review of Cognitive Linguistics 11 (2), pp. 402-416.

Barbe, K. (1995). Irony in Context. Amsterdam \& Philadelphia: John Benjamins.

Bartlett, M. S., Hager, J.C., Ekman P., \& Sejnowski, T. J. (1999). 'Measuring facial expressions by computer image analysis'. Psychophysiology 36 (2), pp. 253-263.

Boxer, D. (2002). Applying Sociolinguistics: Domains and Face-to-Face Interaction. Amsterdam: John Benjamins.

Brône, G. (2007). Bedeuntungskonstitution in verbalem Humor. Ein kognitiv-linguisticher und diskurssemantischer Ansatz. Leuven: University of Leuven PhD Dissertation.

Brône, G. (2008). 'Hyper and misunderstanding in interactional humour'. Journal of Pragmatics 40 (12), pp. 2027-2061.

Brône, G \& Feyaerts, K. (2003). 'The cognitive linguistics of incongruity resolution: Marked reference-point structures in humour'. Leuven: University of Leuven, Department of Linguistics preprint no. 205.

Brône, G., Feyaerts, K. \& Veale, T. (2006). 'Introduction: Cognitive linguistic approaches to humor'. Humor: International Journal of Humor Research 19 (3), pp. 203-228.

Calbris, G. (2008). "From left to right...": Coverbal gestures and their symbolic use of space', in Cienki, A. \& Müller, C. (eds.), Metaphor and Gesture, Amsterdam: John Benjamins, pp. 27-53.

Carston, R. (2002). Thoughts and Utterances: The Pragmatics of Explicit Communication. Oxford: Blackwell.

Carston, R. (2004). 'Relevance theory and the saying/implicating distinction', in Laurence, H. R. \& Ward, G. (eds.), The Handbook of Pragmatics, Oxford: Blackwell, pp. 633-656.

Cienki, A. (2008). 'Why study metaphor and gesture?', in Cienki, A. \& Müller, C. (eds.), Metaphor and Gesture, Amsterdam: John Benjamins, pp. 5-25.

Cheang, H. S. \& Pell M. D. (2009). 'Acoustic markers of sarcasm in Cantonese and English'. Journal of Acoustic Society of America 126 (3), pp. 1394-1405.

Clark, H. H. (1996). Using Language. Cambridge/New York: Cambridge University Press.

Clark, H. H. \& Gerrig R. J. (1984). 'On the pretence theory of irony'. Journal of Experimental Psychology 113 (1), pp. 121-126.

Coulson, S. (2005a). 'Extemporaneous blending: Conceptual integration in humorous discourse from talk radio'. Style 39 (2), pp. 107-122.

Coulson, S. (2005b). 'Sarcasm and the space structuring model', in Coulson, S. \& Lewandowska-Tomasczyk, B. (eds.), The Literal and the Nonliteral in Language and Thought, Berlin: Peter Lang, pp. 129-144.

Croft, W. and Cruse D. A. (2004). Cognitive Linguistics. Cambridge: Cambridge University Press.

Darwin, C. (1872). The Expression of the Emotion in Man and Animals. London: John Murray.

Dynel, M. (2013). 'Humorous phenomena in dramatic discourse'. European Journal of Humour Research 1 (1), pp. 22-60.

Ekman, P. (1979). 'About brows- emotional and conversational signals', in von Cranach, M., Foppa, K., Lepenies, W., \& Ploog, D., (eds.), Human Ethology, Cambridge: Cambridge University Press, pp. 169-248. 
Ekman, P. (1999). 'Emotional and conversational nonverbal signals', in Messing, L. \& Campbell, R. (eds.), Gesture, Speech and Sign, London: Oxford University Press, pp. 4555.

Ekman, P. \& Friesen, W. V. (2003). Unmasking the Face: A Guide to Recognising Emotions from Facial Expressions. Cambridge, Massachusetts: Malor Books.

Fauconnier, G. (1984). Espaces Mentaux. Paris: Les éditions de minuit.

Fauconnier, G. (1994). Mental Spaces: Aspects of Meaning Construction in Natural Language. Cambridge: Cambridge University Press.

Fauconnier, G. \& Turner, M. (1998). 'Conceptual integration networks'. Cognitive Science 22 (2), pp. 133-187.

Feyaerts, K. (2013). 'Tackling the complexity of spontaneous humorous interaction: An integrated classroom-modelled corpus approach', in Ruiz-Gurillo, L. \& Alvarado Ortega, M. B. (eds.), Irony and Humor, Amsterdam \& Philadelphia: John Benjamins, pp. 243-268.

Feyaerts, K., Speelman, D., Brône, G. \& Oben, B. (2007). Corinth: Corpus Interactionele Humor. Leuven: University of Leuven.

Grice, P. (1989). Studies in the Way of Words. Cambridge: Harvard University Press.

Hidalgo Downing, R. \& Iglesias Recuero, S. (2009). 'Humor e ironía: Una relación compleja', in Ruiz Gurillo, L. \& Padilla García, X. A. (eds.), Dime cómo ironizas y te diré quién eres: Una aproximacion pragmática a la ironía, Frankfurt: Peter Lang, pp. 423-455.

Janko, R. (1984). Aristotle on Comedy: Towards a Reconstruction of Poetics II. Berkeley: University of California Press.

Kendon, A. (1980). 'Gesticulation and speech: Two aspects of the process of utterance', in Ritchie, K. M. (ed.), The Relation between Verbal and Nonverbal Communication, The Hague: Mouton, pp. 206-227.

Kihara, Y. (2005). 'The mental space structure of verbal irony'. Cognitive Linguistics, 16 (3), pp. 513-530.

Koestler, A. (1964). The Art of Creation. London: Hutchinson \& Co.

Krauss, R. M., Chen, Y. \& Gottesman, R. F. (2000). 'Lexical gestures and lexical access: A process model', in McNeill, D. (ed.), Language and Gesture, Cambridge: Cambridge University Press, pp. 261-283.

El Rafaie, E. (2011). 'The pragmatics of humor reception: Young people's responses to a newspaper cartoon'. Humor: International Journal of Humor Research 25 (2), pp. 87-108.

Lee, C. J. \& Katz, A. N. (1998). The differential role of ridicule in sarcasm and irony. Metaphor and Symbol 13 (1), pp. 1-15.

McNeill, D. (1985). 'So you think gestures are nonverbal?'. Psychological Review 92 (3), pp. 350-371.

McCarthy, M \& Carter, R. (2004). “"There's millions of them”: Hyperbole in everyday conversation'. Journal of Pragmatics 36 (2), pp. 149-184.

McNeill, D. (1992). Hand and Mind: What Gestures Reveal about Thought. Chicago: University of Chicago Press.

McNeill, D. (2008). 'Unexpected metaphors', in Cienki, A. \& Müller, C. (eds.), Metaphor and Gesture, Amsterdam: John Benjamins, pp. 155-170.

Mesing, J., Williams, D. \& Blasko, D. (2012). 'Sarcasm in relationships: hurtful or humorous?'. International Journal of Psychology 47 (Supp1), pp. 698-743.

Mittelberg, I. (2008). 'Peircean semiotics meets conceptual metaphor: Iconic modes in gestural representations of grammar', in Cienki, A. \& Müller, C. (eds.), Metaphor and Gesture, Amsterdam: John Benjamins, pp. 115-154. 
Müller, C. (1998). Redebegleitende Gesten. Kulturgeschichte - Theorie - Sprachvergleich. Berlin: Verlag A. Spitz.

Perks, L. G. (2012). 'The ancient roots of humour theory'. Humor: International Journal of Humor Research, 25 (2), pp. 119-132.

Radden, G. \& Kövecses, Z. (1999). 'Towards a theory of metonymy', in Klaus-Uwe, P. \& Günter, R. (eds.), Metonymy in Language and Thought, Amsterdam and Philadelphia: John Benjamins, pp. 17-59.

Raskin, V. (1985). Semantic Mechanisms of Humor. Dordrecht: D. Reidel.

Rockwell, P. (2000). 'Lower, slower, louder: Vocal cues to sarcasm'. Journal of Psycholinguistic Research 29 (5), pp. 483-495.

Rockwell, P. (2001). 'Facial expressions and sarcasm'. Perceptual and Motor Skills 93 (1), pp. 47-50.

Sadock, J. M. (1993). 'Figurative speech and linguistics', in Ortony, A. (ed.), Metaphor and Thought. ( $2^{\text {nd }}$ edition), Cambridge \& New York: Cambridge University Press, pp. 42-57.

Sanders, R. E. (2013). 'The duality of speaker meaning: What makes self-repair, insincerity, and sarcasm possible'. Journal of Pragmatics 48 (1), pp. 112-122.

Sloetjes, H. \& Wittenburg, P. (2008). 'Annotation by category: ELAN and ISO DCR', in Proceedings of the $6^{\text {th }}$ International Conference on Language Resources and Evaluation (LREC 2008), pp. 816-820. http:///rec-conf.org/proceedings/lrec2008/pdf/208_paper.pdf (accessed 3 June 2014).

Sperber, D. (1984). 'Verbal irony: Pretence or echoic mention?'. Journal of Experimental Psychology 113 (1), pp. 130-136.

Sperber, D. \& Wilson, D. (1988). Relevance: Communication and Cognition. Cambridge Massachusetts: Harvard University Press.

Sperber, D. \& Wilson, D. (1981). 'Irony and use-mention distinction', in Cole, P. (ed.), Radical Pragmatics, New York: Academic Press, pp. 295-318.

Veale, T., Feyaerts, K. \& Brône, G. (2006). 'The cognitive mechanisms of adversarial humor'. Humor: International Journal of Humor Research 19 (3), pp. 305-338.

Williams, R. (2008). 'Gesture as a conceptual mapping tool', in Cienki, A. \& Müller, C (eds.), Metaphor and Gesture, Amsterdam: John Benjamins, pp. 55-92.

Wilson, D. \& Sperber, D. (2004). 'Relevance theory', in Horn, L. R. \& Ward, G. L. (eds.), The Handbook of Pragmatics, Oxford: Blackwell, pp. 607-632.

Wilson, D. \& Sperber, D. (2012). Meaning and Relevance. Cambridge: Cambridge University Press.

Yus, F. (2003). 'Humour and the search for relevance'. Journal of Pragmatics, 35 (9), pp. 1295-1331. 